\title{
Conhecimentos e expectativas de estudantes ingressantes nos cursos técnicos integrados ao ensino médio do IFSC Campus Criciúma acerca da disciplina de biologia
}

\author{
Knowledge and expectations of students of the technical courses integrated with \\ high school at IFSC Campus Criciúma regarding the subject of biology
}

\author{
Pedro Rosso ${ }^{1}$; Erica Mastella Benincáa ${ }^{2}$ Gabrieli Aparecida Lorenson ${ }^{3}$; \\ Daiana Cardoso Vargas de Figueiredo ${ }^{4}$
}

\begin{abstract}
Resumo
Aproximar os conhecimentos abordados na escola daqueles necessários para a formação pessoal, intelectual, social e profissional dos estudantes é desafiador. Objetivou-se analisar os conhecimentos e expectativas de estudantes de cursos técnicos integrados ao Ensino Médio acerca da disciplina de biologia. Analisaram-se documentos oficiais e aplicou-se um questionário para estudantes de cursos técnicos integrados do Instituto Federal da Santa Catarina, Campus Criciúma. 89,8\% conhece o objeto de estudo da biologia e 30,5\% relacionou os temas de Ciência do Ensino Fundamental com os temas de biologia. Os temas de biologia considerados importantes para a formação pessoal e profissional foram os relacionados à biodiversidade, à anatomia e fisiologia, incluindo as patologias, à origem e evolução da vida e ao estudo da célula.
\end{abstract}

Palavras-Chave: Ciências da natureza. Currículo de biologia. Ensino de biologia.

\section{Abstract}

Bringing the knowledge addressed in school to what is required for the students' personal, intellectual, social and professional qualification is challenging. The objective was to analyze the students' knowledge and expectations about the subject of biology of the technical courses integrated with High School. Official documents were analyzed and a questionnaire was applied to students of the integrated technical courses of Instituto Federal de Santa Catarina, Criciúma campus. 89.8\% knew the object of study of biology, and 30.5\% related themes of Science from Elementary Education with biology. The biology topics considered important for personal and professional qualification were the ones related to biodiversity, anatomy and physiology, including pathologies, the origin and evolution of life and the study o the cell.

Keywords: Nature sciences. Biology curriculum. Biology teaching.

\footnotetext{
${ }^{1}$ Doutor em Biologia Animal - Universidade Federal do Rio Grande do Sul (UFRGS). Porto Alegre, Brasil. Professor de Ensino Básico, Técnico e Tecnológico - Instituto Federal de Educação, Ciência e Tecnologia de Santa Catarina (IFSC). Florianópolis, SC - Brasil. E-mail: pedro.rosso@ifsc.edu.br

2 Mestre em Ciência e Tecnologia Ambiental - Universidade do Vale do Itajaí (UNIVALI). Itajaí, SC Brasil. Docente do Ensino Básico, Técnico e Tecnológico - Instituto Federal de Educação, Ciência e Tecnologia de Santa Catarina (IFSC). Florianópolis, SC - Brasil. E-mail: erica.beninca@ifsc.edu.br

${ }^{3}$ Graduação em Química - Instituto Federal de Educação, Ciência e Tecnologia de Santa Catarina (IFSC). Florianópolis, SC - Brasil. Especialização em andamento - Docência no Ensino Superior - Centro Universitário Leonardo da Vinci, (UNIASSELVI). Benedito, SC - Brasil. E-mail: gabrieliaplorenzon@gmail.com

${ }^{4}$ Graduação em andamento - Licenciatura em Química - Instituto Federal de Educação, Ciência e Tecnologia de Santa Catarina (IFSC). Florianópolis, SC - Brasil. E-mail: daianav752@gmail.com

Submetido em: 18/09/2019 - Aceito em: 09/06/2020
} 


\section{Introdução}

A sociedade muda ao longo do tempo e a escola, como parte da sociedade, também deve mudar. Mudanças estão em curso no Ensino Médio estão em curso e, independente da opinião que se possa ter, é certo vão conduzir a novos momentos neste nível da Educação Básica.

A reforma do Ensino Médio introduziu mudanças na sua organização e, segundo o Ministério da Educação, é um instrumento para a melhoria da educação no país (BRASIL, 2017). Estas mudanças envolvem a adoção de uma parte comum e obrigatória, que é a Base Nacional Comum Curricular (BNCC), e outra em que se permite aos estudantes escolher a área na qual pretendem aprofundar seus estudos (BRASIL, 2017). Nos Institutos Federais, por sua natureza e obrigações legais quanto às modalidades de cursos que ofertam, os estudantes que ingressam no Ensino Médio fazem antecipadamente a opção por uma área profissionalizante em cursos técnicos integrados. É neste contexto que a biologia pode ser uma das disciplinas mais relevantes e merecedoras da atenção dos estudantes ou uma das mais insignificantes, dependendo do que se ensina ou de como isto é feito (KRASILCHIK, 2005), podendo conduzir ou não a uma aprendizagem significativa (KLAUSEN, 2017). Por isso, ao planejar o ensino, é preciso considerar e respeitar os saberes socialmente construídos pelos estudantes (FREIRE, 1996) e aqueles obtidos nos anos anteriores da Educação Básica, o que evidencia a necessidade de os professores terem clareza do que ensinar e de como ensinar (CORADINI; SANGALLI, 2014).

O desafio de aproximar os conhecimentos abordados na escola daqueles necessários para a formação pessoal, intelectual, social e profissional dos estudantes é parte do trabalho do professor. Em relação à disciplina de biologia, é preciso questionar-se continuamente sobre o que os estudantes conhecem a respeito da biologia quando ingressam no Ensino Médio, se eles têm ideia dos temas que serão abordados, o que esperam ou gostariam de aprender durante as aulas ou, ainda, acerca dos temas em biologia que mais lhes despertam mais interesse. Em geral, os professores não têm as respostas para estas e outras questões, porém precisam selecionar os temas e definir como abordá-los nas aulas levando em consideração as diretrizes pedagógicas institucionais e os tempos e espaços de cada curso.

Nos cursos técnicos integrados ao Ensino Médio, a seleção dos temas e a forma como eles serão abordados é ainda mais importante devido ao menor número de aulas previstas nos projetos pedagógicos e o desafio de proporcionar os conhecimentos necessários para a formação pessoal, intelectual, social e profissional dos estudantes. Convém lembrar que a função da educação, de um modo geral, e do Ensino Médio em particular, vai além da formação profissional, devendo proporcionar a construção da cidadania, oferecer aos estudantes novas perspectivas culturais de modo a ampliar seus horizontes e dotá-los de autonomia intelectual, assegurando-lhes o acesso ao conhecimento historicamente acumulado e à produção coletiva de novos conhecimentos, sem perder de vista que a educação é também chave para o exercício 
dos demais direitos sociais (BRASIL, 2013). Como a escola se constitui no espaço de acesso aos saberes da cultura universal e àqueles justificados por um determinado contexto socioeconômico e político (CARVALHO, 2009), é essencial que a seleção dos temas seja bem fundamentada.

Os conteúdos abordados em biologia são, normalmente, fragmentados em áreas temáticas e sem que sejam evidenciadas as relações entre elas (MEGLIORATTI et al., 2009), inclusive nos livros didáticos, além do frequente exagero na quantidade de conteúdos (CARVALHO; NUNES-NETO; EL-HANI, 2011). Nesta forma de abordagem os estudantes, em geral, não conseguem perceber e representar os fenômenos da natureza de forma integrada, transformando a aprendizagem da biologia em um processo de memorização de nomes difíceis (MEGLIORATTI et al., 2009). Para Carvalho, Nunes-Neto e El-Hani (2011), não é possível ensinar tanto conteúdo de forma pouco estruturada e em tão pouco tempo e, ainda, esperar que os estudantes construam uma compreensão significativa e estruturada do mundo vivo.

Mesmo com esta realidade e os desafios a ela associados, o mais comum é que a seleção dos temas de biologia para compor os projetos pedagógicos dos cursos seja pautada em contextos históricos que vem sendo repetidos ao longo do tempo, nas sequências encontradas nos livros didáticos, na afinidade do professor por determinadas áreas ou na combinação das possibilidades acima. Há, ainda, aqueles que levam em consideração o disposto nos documentos oficiais, como a Lei de Diretrizes e Bases da Educação (LDB) (BRASIL, 1996), as Diretrizes Curriculares Nacionais para a Educação Básica (BRASIL, 2013), as Orientações Curriculares para o Ensino Médio (BRASIL, 2006), os Parâmetros Curriculares Nacionais para o Ensino Médio (BRASIL, 2014) e, mais recentemente, a Base Nacional Comum Curricular (BRASIL, 2018).

Uma das formas de minimizar estes problemas é diagnosticar os conhecimentos e expectativas dos estudantes acerca da biologia e utilizá-los na seleção dos conteúdos. Para Krasilchik (2005), os conhecimentos biológicos devem contribuir para que o indivíduo seja capaz de compreender as explicações de processos e conceitos biológicos e a importância da ciência e da tecnologia na vida moderna, além de interessar-se pelo mundo dos seres vivos. Ainda, segundo a mesma autora, os conhecimentos biológicos devem contribuir para que o cidadão seja capaz de tomar decisões de caráter individual e/ou coletivo considerando o papel e a responsabilidade do ser humano na biosfera. Assim, "os conteúdos de biologia devem propiciar condições para que o estudante compreenda a vida como manifestação de sistemas organizados e integrados, em constante interação com o ambiente físico-químico" (BRASIL, 2006, p. 20).

Neste contexto, o presente estudo teve como objetivo analisar os conhecimentos e expectativas dos estudantes ingressantes dos cursos técnicos integrados ao Ensino Médio do Instituto Federal de Santa Catarina (IFSC), Campus Criciúma, acerca da disciplina de biologia com vistas a subsidiar os professores da área na tarefa de selecionar os temas a serem abordados nas aulas. Também se buscou analisar os temas previstos para a disciplina de biologia nos 
atuais projetos pedagógicos dos cursos ofertados no IFSC Campus Criciúma à luz dos documentos oficiais e das informações da pesquisa com vistas a disponibilizá-las para servirem de apoio em futuras revisões dos mesmos.

\section{Materiais e métodos}

A pesquisa é a chave para a formação de indivíduos que atuem com olhar científico e indagador e que tenham a capacidade de questionarem e intervirem na realidade. Neste sentido, buscaram-se informações que pudessem contribuir para aproximar os conhecimentos e as expectativas dos estudantes do planejamento desta disciplina em cursos técnicos integrados ao Ensino Médio. Trata-se de uma pesquisa descritiva, pois nela se buscou descobrir a frequência com que um fenômeno ocorre, sua natureza, características, causas, relações e conexões com outros fenômenos (BARROS; LEHFELD, 2007).

Foram estudados os documentos oficiais que norteiam a Educação Básica e Profissional disponíveis em sítios oficiais. Em paralelo aos estudos, foi realizado um levantamento qualiquantitativo com os 118 estudantes que ingressaram em 2018 nos três cursos técnicos integrados ao Ensino Médio ofertados no IFSC Campus Criciúma por meio da aplicação de questionário semiestruturado (BARROS; LEHFELD, 2007) contendo cinco questões, as quais foram respondidas pelos próprios estudantes. Antes da aplicação do questionário os estudantes foram informados sobre os objetivos da pesquisa e a posterior utilização dos dados em publicação científica, além do compromisso dos pesquisadores com a manutenção do anonimato quando da divulgação dos resultados e a liberdade de não participarem da pesquisa.

Os dados obtidos foram sistematizados, analisados e correlacionados com as informações relativas à biologia presentes nos documentos oficiais e nos projetos pedagógicos dos cursos técnicos integrados ao Ensino Médio ofertados no IFSC Campus Criciúma.

\section{Resultados e discussão}

Os 118 estudantes que preencheram os questionários cursavam, em 2018, o $1^{\circ}$ Ano em um dos cursos técnicos integrados ao Ensino Médio ofertados no IFSC Campus Criciúma, sendo 40 em Edificações, 38 em Mecatrônica e 40 em Química.

A maioria (89,8\%) afirmou conhecer o objeto de estudo da biologia (Figura 1) e 27 temas distintos foram relatados como tal. Dentre eles, destacam-se o estudo dos seres vivos $(21,0 \%)$, da vida $(13,8 \%)$, da origem da vida e evolução dos seres vivos $(13,7 \%)$, dos animais $(9,1 \%)$, da natureza, meio ambiente e ecossistemas $(6,9 \%)$ e das plantas $(6,5 \%)$, o que indica que, de algum modo, compreendem os seres vivos como objeto de estudo da biologia. Muitos estudantes, além de indicar o objeto de estudo, citaram exemplos ou expuseram detalhes para explicar as respostas. Este resultado era esperado, pois os questionários foram aplicados aproximadamente dois meses após o início das aulas e, em duas das três turmas, a disciplina de biologia já havia sido iniciada, pois consta da matriz curricular desde o $1^{\circ}$ Ano. Entre os 
estudantes do curso em Mecatrônica, único a não ter a disciplina de biologia na matriz curricular do $1^{\circ}$ Ano, 27,5\% dos estudantes afirmou não conhecer o objeto de estudo da disciplina (Figura 1).

Figura 1 - Percentual de estudantes que relatou conhecer o objeto de estudo da biologia, segundo o curso técnico integrado ao Ensino Médio (CTI) que frequentavam e no total.

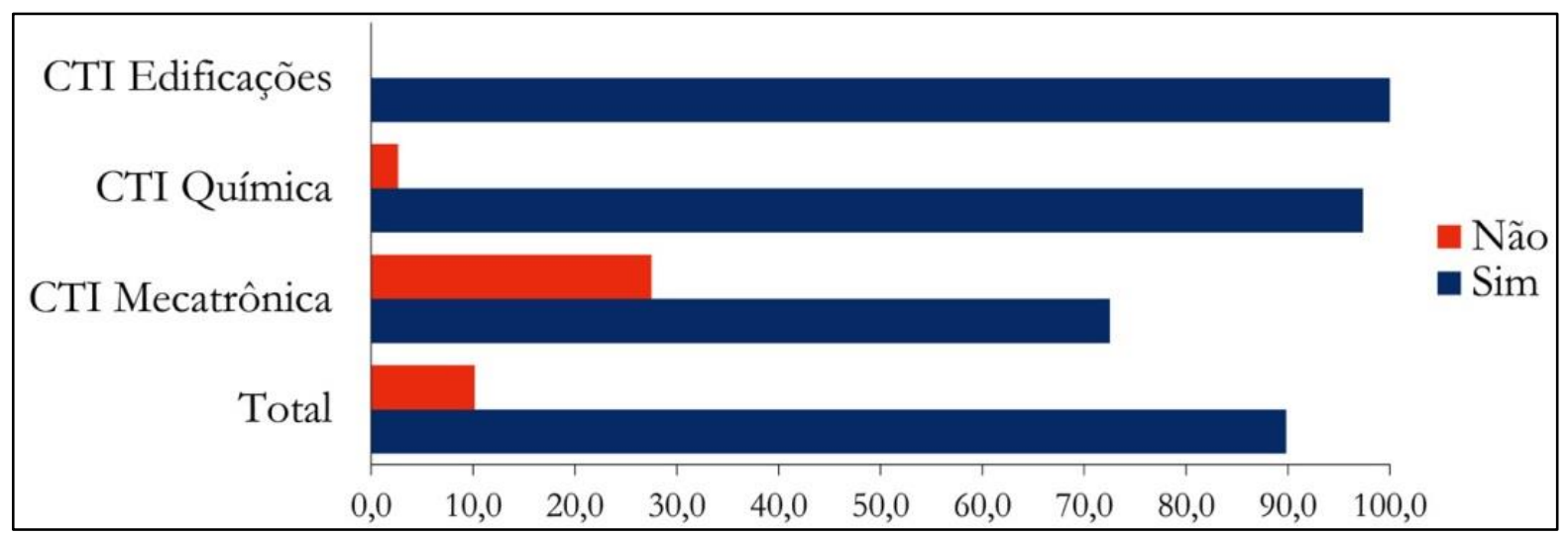

Fonte: Elaborado pelos autores.

A maioria dos estudantes $(63,6 \%)$ relatou não ter frequentado aulas de biologia em anos letivos anteriores ao da pesquisa e apenas 5,9\% cursaram o $1^{\circ}$ Ano em 2017 e optaram por ingressar no IFSC em 2018, ou já eram estudantes do IFSC e reprovaram em 2017 (Figura 2). Os temas mais lembrados, inclusive por aqueles oriundos do Ensino Fundamental (EF), foram relacionados ao estudo das células e sobre reprodução e, em menores frequências, temas relacionados ao ácido desoxirribonucleico (ADN), às doenças sexualmente transmissíveis (DST's), à origem e evolução dos seres vivos, à hereditariedade, às características dos seres vivos e à biodiversidade. Nota-se que com maior ou menor profundidade os temas citados estão entre os mais frequentemente encontrados nos livros didáticos elaborados para uso no $1^{\circ}$ Ano do Ensino Médio. Também nos projetos pedagógicos dos cursos ofertados no IFSC Campus Criciúma estes temas estão entre os programados para o $1^{\circ}$ Ano ou, no caso do curso em Mecatrônica, para o $2^{\circ}$ Ano. A partir destes resultados infere-se que o livro didático foi, possivelmente, o principal instrumento utilizado na seleção dos conteúdos, corroborando a afirmação de Krasilchic (2005) de que o mesmo tem adquirido importante papel tanto na determinação do conteúdo como nos métodos utilizados no ensino de biologia. 
Figura 2 - Percentual de estudantes que relataram terem estudado conteúdos de biologia em anos anteriores letivos ao da pesquisa.

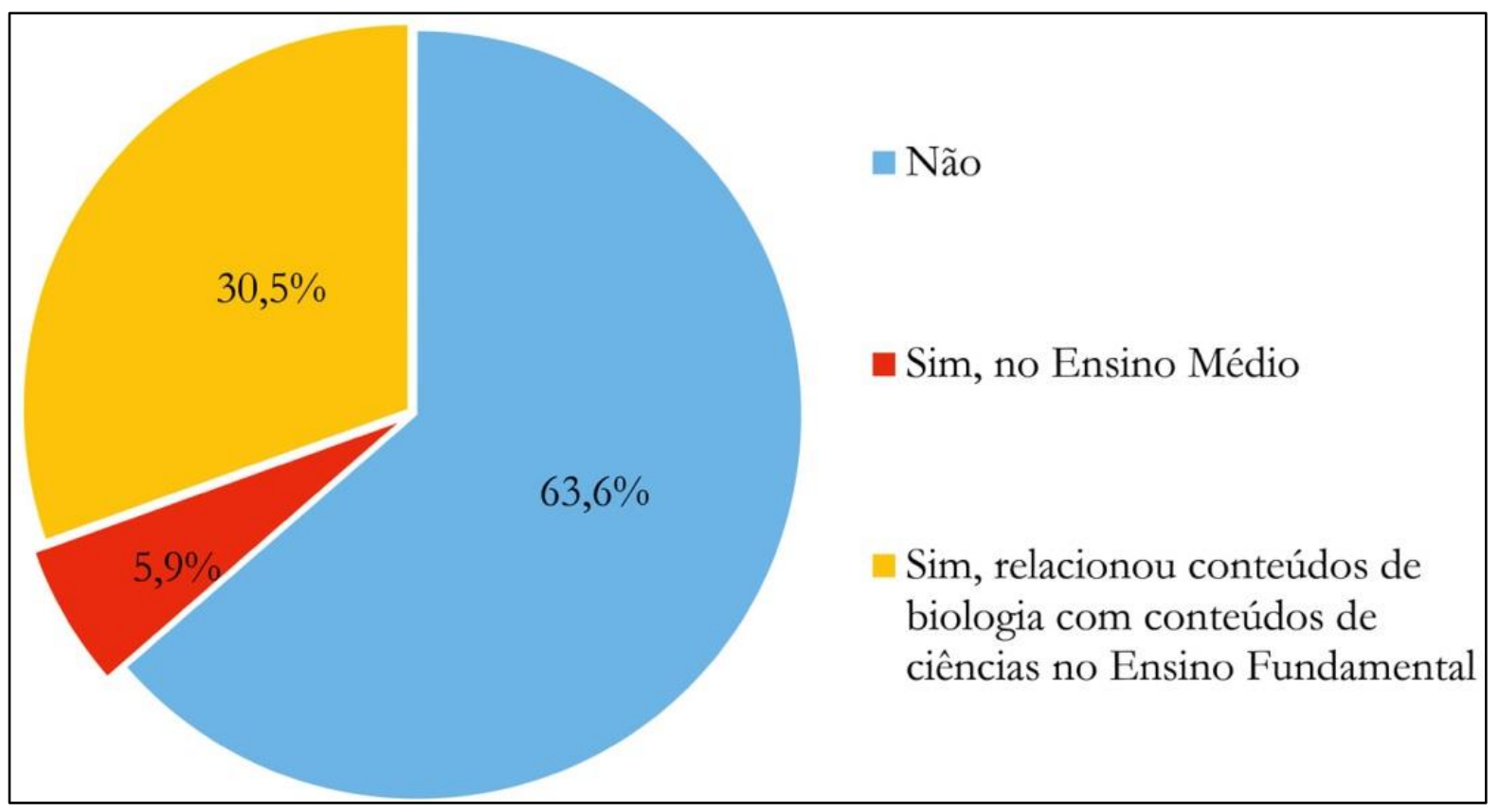

Fonte: Elaborado pelos autores.

Apesar de não terem frequentado aulas de biologia em anos anteriores a pesquisa, $30,5 \%$ dos estudantes relacionaram os temas estudados na disciplina de ciências durante o Ensino Fundamental com os que acreditam ser o conteúdo de biologia (Figura 2). Ao fazerem esta correlação, demonstram que a aprendizagem destes temas foi significativa. Para Rogers (2001 apud KLAUSEN, 2017), aprendizagem significativa é mais do que uma acumulação de fatos e provoca uma modificação que não se limita a um aumento de conhecimento, mas penetra e permanece. Para Klausen (2017), uma aprendizagem significativa envolve a compreensão de significados, relacionando-os às experiências anteriores e vivências pessoais e permitindo a formulação de problemas desafiantes que incentivem a aprender mais. Neste contexto, Caldeira e Bastos (2009) afirmam que as ciências da natureza possuem características próprias em termos de objetos de estudo, metas, métodos de pesquisa, linguagens empregadas e tipos de produtos finais disponibilizados, independente do nível e da profundidade da abordagem na escola. Estas características das ciências da natureza associadas à aprendizagem significativa de temas relacionados à ecologia e biodiversidade e à anatomia e fisiologia do corpo humano no Ensino Fundamental motivaram os estudantes a associar tais temas com a disciplina de biologia. Estes temas, de fato, estavam entre os programados para a disciplina de ciências no Ensino Fundamental de acordo com os Parâmetros Curriculares (BRASIL, 1998) e, atualmente, estão entre os relacionados para a mesma disciplina na Base Nacional Comum Curricular para o Ensino Fundamental (BRASIL, 2018). Também, com maior ou menor grau de abrangência, são temas que estavam relacionados para a disciplina de biologia nas Orientações Educacionais Complementares aos Parâmetros Curriculares Nacionais para a área 
de ciências da natureza no Ensino Médio (BRASIL, 2014) e atualmente se inserem nas competências previstas na Base Nacional Comum Curricular para o Ensino Médio (BRASIL, 2018).

Embora quase um terço dos estudantes tenha correlacionado espontaneamente os conteúdos de ciências no Ensino Fundamental com os de biologia na segunda questão, a questão seguinte os instigava a indicarem os temas estudados em ciências que acreditavam ser relacionados à biologia. Os seis primeiros blocos de respostas agrupadas $(73,5 \%)$ confirmaram a correlação já indicada na questão anterior. Contudo, destaca-se que temas relacionados à anatomia e fisiologia humana foram os mais citados por estudantes do curso em Mecatrônica, enquanto que temas diretamente relacionados ao objeto de estudo da biologia foram os mais citados por estudantes dos cursos em Edificações e Química, embora os relacionados à citologia e anatomia e fisiologia humana também apareceram com relativa frequência (Tabela 1).

Tabela 1 - Número de indicações por grupos de temas que os estudantes relataram terem estudados em anos anteriores e que acreditam serem conteúdos de biologia, segundo o Curso Técnico Integrado ao Ensino Médio (CTI) que frequentam, total e percentual.

\begin{tabular}{|c|c|c|c|c|c|}
\hline Grupos de temas & $\begin{array}{c}\text { CTI } \\
\text { Edificações }\end{array}$ & $\begin{array}{c}\text { CTI } \\
\text { Química }\end{array}$ & $\begin{array}{c}\text { CTI } \\
\text { Mecatrônica }\end{array}$ & Total & $\%$ \\
\hline Biodiversidade (Vida, Seres vivos e Classificação, Reinos, Organismos) & 32 & 27 & 18 & 77 & 22,4 \\
\hline Anatomia e Fisiologia (Corpo Humano, Sistemas do corpo, Órgãos) & 12 & 22 & 25 & 59 & 17,2 \\
\hline Citologia (Células) & 16 & 20 & 8 & 44 & 12,8 \\
\hline Zoologia (Animais, Classificação dos animais) & 12 & 9 & 13 & 34 & 9,9 \\
\hline Botânica (Plantas) & 7 & 11 & 12 & 30 & 8,7 \\
\hline Origem e Evolução da vida(Adaptação, Teoria do Big-Bang, Terra primitiva) & 14 & 10 & 4 & 28 & 8,1 \\
\hline Ecologia (Meio ambiente, Natureza, Cadeia alimentar, Ecossistemas, Biomas) & 2 & 7 & 8 & 17 & 4,9 \\
\hline Doenças & 12 & 2 & 2 & 16 & 4,7 \\
\hline Microbiologia (Microrganismos, Bactérias, Fungos, Vírus) & 2 & 5 & 5 & 12 & 3,5 \\
\hline Reprodução & 5 & 3 & 2 & 10 & 2,9 \\
\hline Alimentação (Alimentos) & 0 & 3 & 3 & 6 & 1,7 \\
\hline Universo, Sistema Solar, Terra, Planeta Terra, Rochas, Solo & 0 & 2 & 4 & 6 & 1,7 \\
\hline Átomo, Formação molecular & 3 & 1 & 1 & 5 & 1,5 \\
\hline Totais & 117 & 122 & 105 & 344 & 100,0 \\
\hline
\end{tabular}

Fonte: Elaboração dos autores.

Assim como ocorreu na primeira questão, o período de aplicação pode ter influenciado as respostas dos estudantes dos cursos em Edificações e Química. Apesar disto, os resultados, especialmente aqueles obtidos junto aos estudantes do curso em Mecatrônica, reforçam o que Caldeira e Bastos (2009) relatam sobre as características das ciências da natureza e a compreensão de significados, relacionando-os às experiências e vivências, e que Klausen (2017) refere como aprendizagem significativa. 
Os temas relacionados ao estudo da biodiversidade (26,6\%), incluindo os relativos à classificação, comportamento e papel dos organismos no ambiente, somados aos estudos ecológicos $(6,9 \%)$, foram relatados como importantes para a formação pessoal (Tabela 2). Tais dados permitem inferir que os estudantes têm preocupação com a natureza e sua preservação e são bons indicativos do trabalho realizado sobre este assunto durante o Ensino Fundamental e de que as temáticas previstas nos documentos oficiais (BRASIL, 1998; 2018) estão sendo abordadas nas aulas. Por outro lado, amplia a responsabilidade dos professores de biologia, pois esta é um importante meio para que os estudantes ampliem sua compreensão sobre a realidade, percebendo e interpretando os fenômenos biológicos, além de ser um instrumento para orientar decisões e intervenções na natureza (BRASIL, 2014). Estudos relacionados ao estudo corpo humano $(23,2 \%)$ e à origem e evolução da vida $(15,8 \%)$ também foram considerados como importantes para a formação pessoal (Tabela 2). Contudo, a indicação destes temas não foi uniforme entre os cursos e os dados não nos permitem inferir justificativas para as diferenças observadas.

Tabela 2 - Número de indicações por grupos de temas de biologia que os estudantes relataram serem mais importantes para a formação pessoal, segundo o Curso Técnico Integrado ao Ensino Médio (CTI) que frequentam, total e percentual.

\begin{tabular}{|c|c|c|c|c|c|}
\hline Grupos de temas & $\begin{array}{c}\text { CTI } \\
\text { Edificações }\end{array}$ & $\begin{array}{c}\text { CTI } \\
\text { Química }\end{array}$ & $\begin{array}{c}\text { CTI } \\
\text { Mecatrônica }\end{array}$ & Total & $\%$ \\
\hline Biodiversidade (Reinos, Seres vivos, Animais, Plantas, Bactérias, Fungos) & 20 & 20 & 14 & 54 & 26,6 \\
\hline $\begin{array}{l}\text { Anatomia e Fisiologia (Corpo humano, Organismos e sistemas, Órgãos, } \\
\text { Reprodução, Alimentação) }\end{array}$ & 8 & 27 & 12 & 47 & 23,2 \\
\hline Origem e Evolução da Vida (Adaptação) & 24 & 3 & 5 & 32 & 15,8 \\
\hline Ecologia (Planeta, Natureza, Solo) & 4 & 4 & 6 & 14 & 6,9 \\
\hline Patologias (Doenças, Microrganismos, Vírus) & 6 & 11 & 7 & 24 & 11,8 \\
\hline Citologia & 2 & 5 & 2 & 9 & 4,4 \\
\hline Genética & 1 & 1 & 0 & 2 & 1,0 \\
\hline Bioquímica (Biotecnologia) & 0 & 0 & 3 & 3 & 1,5 \\
\hline Não sabe/Não respondeu & 1 & 3 & 9 & 13 & 6,4 \\
\hline Composição química dos materiais & 0 & 3 & 2 & 5 & 2,5 \\
\hline Total & 66 & 77 & 60 & 203 & 100,0 \\
\hline
\end{tabular}

Fonte: Dados da pesquisa.

Os temas relacionados à anatomia e fisiologia humana foram os mais citados como importantes para a formação profissional pelos estudantes dos cursos em Edificações e Mecatrônica, enquanto os estudantes do curso em Química indicaram os temas relacionados à Bioquímica. Contudo, temas relacionados aos estudos ecológicos, da biodiversidade e sobre a origem e evolução da vida estão entre os mais citados no conjunto das respostas (32\%) (Tabela 3). Ressalta-se que $15,5 \%$ dos estudantes não responderam, não souberam responder ou relataram que tudo é importante, indicando desconhecimento do itinerário formativo do curso ou da área para a qual fizeram opção profissional ou, então, que ainda não haviam conseguido estabelecer correlações entre estes e os temas de biologia que conhecem ou tem expectativa de conhecer durante o curso. Frisa-se, no entanto, que não se questionou ou fez-se qualquer referência ao projeto de vida dos estudantes para depois do Ensino Médio, nem se a opção por 
um curso profissionalizante foi pessoal, decisão familiar ou por ser o IFSC uma instituição pública federal. Observa-se, contudo, que relatos informais dos estudantes durante as atividades docentes destes pesquisadores e de outros docentes da instituição levam a acreditar que muitos têm a instituição como referência em qualidade de ensino e que, por isto, pode auxiliá-los na conquista de uma vaga no Ensino Superior.

Tabela 3 - Número de indicações por grupos de temas de biologia que os estudantes consideram que mais contribuiriam para a formação profissional, segundo o Curso Técnico Integrado ao Ensino Médio (CTI) que frequentam, total e percentual.

\begin{tabular}{lccccc}
\hline \multicolumn{1}{c}{ Grupos de temas } & $\begin{array}{c}\text { CTI } \\
\text { Edificações }\end{array}$ & $\begin{array}{c}\text { CTI } \\
\text { Química }\end{array}$ & $\begin{array}{c}\text { CTI } \\
\text { Mecatrônica }\end{array}$ & Total & \% \\
\hline Anatomia e fisiologia humana & 15 & 7 & 21 & 43 & 22,2 \\
Biodiversidade & 13 & 8 & 5 & 26 & 13,4 \\
Ecologia & 10 & 2 & 7 & 19 & 9,8 \\
Origem e evolução da vida & 9 & 5 & 3 & 17 & 8,8 \\
Bioquímica & 0 & 13 & 2 & 15 & 7,7 \\
Microbiologia & 2 & 3 & 7 & 12 & 6,2 \\
Biotecnologia & 0 & 5 & 3 & 8 & 4,1 \\
Patologias & 3 & 1 & 2 & 6 & 3,1 \\
Genética & 0 & 2 & 1 & 3 & 1,5 \\
Citologia & 0 & 2 & 1 & 3 & 1,5 \\
Não sei/Não respondeu/Tudo é importante & 10 & 9 & 11 & 30 & 15,5 \\
Não se aplica & 1 & 4 & 7 & 12 & 6,2 \\
\hline Totais & $\mathbf{6 3}$ & $\mathbf{6 1}$ & $\mathbf{7 0}$ & $\mathbf{1 9 4}$ & $\mathbf{1 0 0 , 0}$ \\
\hline
\end{tabular}

Fonte: Dados da pesquisa.

Embora os Institutos Federais sejam instituições especializadas na oferta de educação profissional e tecnológica (Art. 2º , Lei 11.892/2008) (BRASIL, 2008), como instituição de ensino se constitui também, como afirma Carvalho (2009), num espaço de acesso aos saberes da cultura universal. Assim, é fundamental que a seleção dos temas, seja para qual for a disciplina, esteja fundamentada da melhor maneira possível, sem se restringir ao historicamente estabelecido, ao que está no livro didático ou na opção pessoal do docente. Embora exista fragmentação dos conteúdos de biologia em áreas temáticas, como mencionam Meglioratti et al. (2009), cabe ao professor evidenciar a relação entre elas de modo a facilitar aos estudantes a percepção e representação integrada dos fenômenos da natureza. 


\section{Conclusão}

Construir o projeto pedagógico de um curso é o primeiro desafio em uma instituição de ensino, pois é necessário combinar a diretriz pedagógica, o itinerário formativo, a distribuição de unidades curriculares e seus temas com os tempos e espaços. As mudanças no Ensino Médio exigem que os envolvidos debatam estas questões, minimizem as arestas e interesses pessoais e busquem um consenso que responda de forma mais coerente sobre para que e para qual público se destina aquele curso. A biologia faz parte deste contexto.

Esta pesquisa demonstrou que os temas abordados em biologia nos cursos técnicos integrados no IFSC Campus Criciúma não estão distantes daqueles que fazem parte do conhecimento e das expectativas dos estudantes ingressantes. Neste sentido, temas relacionados aos estudos sobre a biodiversidade e sobre a célula estão contemplados, enquanto temas relacionados aos estudos ecológicos, sobre anatomia e fisiologia humana, incluindo patologias, e sobre a origem e evolução da vida não fazem parte explicitamente do rol de temas encontrados nos projetos pedagógicos dos cursos. Contudo, estes temas são, de alguma maneira, contemplados nas aulas, muitas vezes por conta de questões apresentadas pelos próprios estudantes. Em relação à anatomia e fisiologia humana, apenas o tema reprodução humana encontra-se contemplado nos projetos pedagógicos. Entre as razões para esta situação está o fato de que a instituição desenvolve cursos profissionalizantes e que estes tem uma carga horária mínima definida pelo Catálogo Nacional de Cursos Técnicos que deve ser destinada às unidades curriculares profissionalizantes. Desse modo, as demais áreas que compõem o Ensino Médio precisam fazer ajustes nos tempos e espaços restantes, em geral excluindo temas.

As informações obtidas neste estudo apontaram para a importância da abordagem de temas relacionados à biodiversidade, à anatomia e fisiologia humana, à origem e evolução da vida e ao estudo da célula, cabendo ao professor adotar a abrangência e profundidade de abordagem. Com isto a biologia poderá contribuir, no contexto das ciências da natureza, para o desenvolvimento do pensamento científico com vistas a sua aplicação em contextos diversos.

\section{Agradecimentos}

Ao Instituto Federal de Santa Catarina, que por meio da Pró-Reitoria de Pesquisa, PósGraduação e Inovação (PROPPI) concedeu apoio financeiro e bolsas concedidas no âmbito do Edital no 34/2017/PROPPI/DAE/Chamada 2017.2. 


\section{Referências}

BARROS, Aidil Jesus da Silveira; LEHFELD, Neide Aparecida de Souza. Fundamentos de metodologia científica. 3. ed. São Paulo: Pearson Prentice Hall, 2007. 158 p.

BRASIL. Lei n. 9.394, de 20 de dezembro de 1996. Estabelece as diretrizes e bases da educação nacional. Disponível em: http://www.planalto.gov.br/ccivil_03/LEIS/L9394.htm. Acesso em: 02 abr. 2019.

BRASIL. Lei n. 11.892, de 29 de dezembro de 2008. Institui a Rede Federal de Educação Profissional, Científica e Tecnológica, cria os Institutos Federais de Educação, Ciência e Tecnologia, e dá outras providências. Disponível em:

http://www.planalto.gov.br/ccivil_03/_Ato2007-2010/2008/Lei/L11892.htm. Acesso em: 02 abr. 2019.

BRASIL. Ministério da Educação. Novo ensino médio: Dúvidas. Disponível em: http://portal.mec.gov.br/component/content/article?id=40361\#nem_01. Acesso em: 28 out. 2017.

BRASIL. Ministério da Educação. PCN+Ensino Médio: Orientações Educacionais Complementares aos Parâmetros Curriculares Nacionais: Ciências da Natureza, Matemática e suas Tecnologias: Brasília: MEC, 2014. Disponível em:

http://portal.mec.gov.br/seb/arquivos/pdf/CienciasNatureza.pdf. Acesso em: 12 mar. 2018.

BRASIL. Ministério da Educação, Secretaria de Educação Básica. Orientações curriculares para o ensino médio: ciências da natureza, matemática e suas tecnologias. v. 2. Brasília: Ministério da Educação, Secretaria de Educação Básica, 2006. 137 p. Disponível em: http://portal.mec.gov.br/seb/arquivos/pdf/book_volume_02_internet.pdf. Acesso em: 29 out. 2017.

BRASIL. Ministério da Educação. Secretaria da Educação Básica. Base Nacional Comum Curricular: educação é a base. Brasília: Ministério da Educação, Secretaria de Educação Básica, 2018. Disponível em: http://basenacionalcomum.mec.gov.br/wpcontent/uploads/2018/12/BNCC_19dez2018_site.pdf. Acesso em: 02 abr. 2019.

BRASIL. Ministério da Educação. Secretaria de Educação Básica. Secretaria de Educação Continuada, Alfabetização, Diversidade e Inclusão. Secretaria de Educação Profissional e Tecnológica. Conselho Nacional da Educação. Câmara Nacional de Educação Básica.

Diretrizes curriculares nacionais gerais da educação básica. Brasília: MEC, SEB, DICEI, 2013. 562p. Disponível em:

http://portal.mec.gov.br/index.php?option=com_docman\&view=download\&alias=13448diretrizes-curiculares-nacionais-2013-pdf\&Itemid=30192. Acesso em: 29 out. 2017.

BRASIL. Ministério da Educação. Secretaria de Educação Fundamental. Parâmetros 
curriculares nacionais: ciências naturais. Brasília: MEC/SEF, 1998. 138 p. Disponível em: http://portal.mec.gov.br/seb/arquivos/pdf/ciencias.pdf. Acesso em: 14 jul. 2018.

CALDEIRA, Ana Maria de Andrade; BASTOS, Fernando. A didática como área do conhecimento. In: CALDEIRA, Ana Maria de Andrade; ARAÚJO, Elaine S. Nicolini Nabuco de (Org.). Introdução à didática da biologia. São Paulo: Escrituras, 2009. p. 20-43.

CARVALHO, Graça Simões de. A transposição didáctica e o ensino da biologia. In: CALDEIRA, Ana Maria de Andrade; ARAÚJO, Elaine S. Nicolini Nabuco de (Org.). Introdução à didática da biologia. São Paulo: Escrituras, 2009. p. 44-70.

CARVALHO, Ítalo Nascimento; NUNES-NETO, Nei Freitas; EL-HANI, Charbel N. Como selecionar conteúdos de biologia para o ensino médio. Revista de Educação, Ciências e Matemática, v. 1, n. 1, ago./dez. 2011. Disponível em:

http://publicacoes.unigranrio.edu.br/index.php/recm/article/view/1588/774. Acesso em: 14 jul. 2018.

CORADINI, Amanda; SANGALLI, Andréia. Ensino de Biologia: o que os estudantes do Ensino Médio pensam sobre os conteúdos e metodologias. In: ENEPEX - Encontro de Ensino, Pesquisa e Extensão (UEMS/UFGD), 2014. Anais.... Disponível em: http://eventos.ufgd.edu.br/enepex/anais/arquivos/28.pdf. Acesso em: 29 out. 2017.

FREIRE, Paulo. Pedagogia da autonomia: saberes necessários à prática educativa. São Paulo: Paz e Terra, 1996. 148 p.

KLAUSEN, Luciana dos Santos. Aprendizagem significativa: um desafio. In: EDUCERE Congresso Nacional de Educação, 13., 2017, Curitiba. Anais .... Curitiba:

Champagnat/PUCPR, 2017. p. 6403-6411. Disponível em: http://educere.bruc.com.br/arquivo/pdf2017/25702_12706.pdf. Acesso em: 19/06/2018.

KRASILCHIK, Myriam. Práticas de ensino de biologia. 4. ed. São Paulo: EDUSP, 2005.

MEGLIORATTI, Fernanda A.; BRANDO, Fernanda Rocha; ANDRADE, Mariana A. B. S.; CALDEIRAS, Ana Maria de Andrade. A integração conceitual no Ensino de Biologia: uma proposta hierárquica de organização do conhecimento biológico. In: CALDEIRA, Ana Maria de Andrade; ARAÚJO, Elaine S. Nicolini Nabuco de (Org.). Introdução à didática da biologia. São Paulo: Escrituras, 2009. p. 219-237. 